EGU2020-3448

https://doi.org/10.5194/egusphere-egu2020-3448

EGU General Assembly 2020

(c) Author(s) 2020. This work is distributed under

the Creative Commons Attribution 4.0 License.

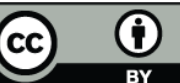

\title{
Effects of climate change on the Nossana karst spring (northern Italy): future discharge projections and water distribution system sustainability
}

Corrado Camera, Andrea Citrini, and Giovanni Pietro Beretta

Università degli Studi di Milano, Dipartimento di Scienze della Terra 'A. Desio'; Milano, Italy (corrado.camera@unimi.it)

Nossana represents an important pre-Alpine karst spring located in Lombardy Region (Northern Italy). It is used for drinking supply and it sustains a water distribution system serving 300,000 people, including the city of Bergamo. The objective of this study was to project Nossana discharges, to evaluate potential supply limits for four future periods (2021-2040, 2041-2060, 2061-2080, 2081-2100). The study was carried out following a four-step approach. First, the EUROCORDEX bias-corrected Regional Climate Models (RCMs) available for all the emission scenarios (RCP2.6, RCP4.5, RCP8.5) were evaluated in terms of precipitation and temperature monthly climatology. Second, they were statistically downscaled by means of change factors and a stochastic weather generator. Third, a rainfall-runoff model ensemble accounting also for snow dynamics (GR4J with CemaNeige module) was calibrated and validated on historical time series (1998-2017). Finally, the future downscaled time series were used as input in the calibrated model and the projected discharges evaluated in terms of low flow. In detail, two warning discharge thresholds - one for high water demand periods and one for ordinary water demand periods were recognized with the service company managing the spring (Uniacque S.p.A.). Then, the number of (consecutive) days below them were calculated for each future period and compared to the historical time series. For each emission scenario, the calibrated model ensemble counted three RCMs and ten rainfall-runoff parameterizations. Projected ensemble mean discharges are lower than observations for all future periods and RCPs (from -3\% for 2021-2040 and RCP4.5 to $-23 \%$ for 2081-2100 and RCP8.5), although they do not show a clear trend between the four time periods. Days characterized by discharges lower than the warning thresholds are projected to decrease except for the RCP8.5 emission scenarios and the period 2081-2100 (14\% increase for the ordinary-demand threshold, $10 \%$ increase for the high-demand threshold). Conversely, consecutive days are expected to increase between 2061 and 2100 for all emission scenarios and the two thresholds (by $0 \%$ and $26 \%$ for RCP 2.6 , by $8 \%$ and $15 \%$ for RCP 4.5 , by $28 \%$ and $48 \%$ for RCP 8.5). These results reflect the projected precipitation trend, characterized by longer, drier summer periods and wetter autumns in comparison to today's climate. Also, they indicate the need to develop a plan for the research and use of alternative drinking water resources for the long-term period. Therefore, the proposed methodology demonstrated to deliver useful information for water management planning. Future studies are intended to focus on chemistry and isotopic composition of water. 
